\title{
Unraveling magnetic fabrics
}

Journal Article

Author(s):

Hirt, Ann Marie (D); Almqvist, Bjarne S.G.

Publication date:

2012-04

Permanent link:

https://doi.org/10.3929/ethz-b-000049232

Rights / license:

In Copyright - Non-Commercial Use Permitted

Originally published in:

International Journal of Earth Sciences 101(3), https://doi.org/10.1007/s00531-011-0664-0 


\title{
Unraveling magnetic fabrics
}

\author{
Ann M. Hirt • Bjarne S. G. Almqvist
}

Received: 30 July 2010/Accepted: 15 April 2011/Published online: 6 May 2011

(C) Springer-Verlag 2011

\begin{abstract}
The anisotropy of magnetic susceptibility has been proven to be an excellent indicator for mineral fabrics and therefore deformation in a rock or sediment. Low-field anisotropy is relatively rapid to measure so that a sufficient number of samples can be measured to obtain a good statistical representation of the magnetic fabric. The physical properties of individual minerals that contribute to the observed magnetic fabric include bulk susceptibility and intrinsic anisotropy of the mineral phase, its volume concentration, and its degree of alignment. Several techniques have been developed to separate magnetic subfabrics arising from magnetization types, i.e., ferrimagnetism, antiferromagnetism, paramagnetism, and diamagnetism. Susceptibility anisotropy can be measured in low or high fields and at different temperatures in order to isolate a particular subfabric. Measuring the anisotropy of a remanent magnetization can also isolate ferrimagnetic fabrics. A series of case studies are presented that exemplify the value of isolating magnetic subfabrics in a geological context. It is particularly useful in rocks that carry a paramagnetic and diamagnetic subfabric of similar magnitude, such that they negate one another. Further examples are provided for purely paramagnetic subfabrics and cases where a ferrimagnetic subfabric is also identified.
\end{abstract}

Keywords Magnetic anisotropy .

Diamagnetic anisotropy · Paramagnetic anisotropy .

Ferromagnetic anisotropy $\cdot$ Magnetic subfabrics

A. M. Hirt $(\bowtie) \cdot$ B. S. G. Almqvist

Institute of Geophysics, ETH-Zurich, Sonneggstrasse 5,

8092 Zurich, Switzerland

e-mail: ann.hirt@erdw.ethz.ch

\section{Introduction}

More than 50 years ago, Graham (1954) suggested that ferromagnetic (s.l.) minerals realign when a rock is deformed and therefore that the magnetic susceptibility anisotropy may be useful in solving problems related to petrofabrics and structure. Balsley and Buddington (1960) demonstrated that low-field anisotropy of magnetic susceptibility (LF-AMS) was capable of detecting fabrics in granite and orthogneiss from the Adirondacks on a microscopic scale that were not visible on a macroscopic scale. At the same time, Fuller $(1960,1963,1964)$ examined the magnetic fabric in the Welsh slates and noted that the maximum axes of the LF-AMS agree with the direction of long axes of mica crystals in the slates. Due to the high degree of anisotropy, he attributed pyrrhotite as the carrier of the observed magnetic fabric (Fuller 1964). In a second seminal study, Graham (1966) recognized that LF-AMS mirrored progressive deformation in deformed sedimentary rocks from the Appalachian mountain belt. Several key studies appeared in the late 1970s and early 1980s relating LF-AMS to strain in different rocks (Hrouda 1979; Hrouda and Janák 1976; Kligfield et al. 1977, 1981, 1982; Kneen 1976). Kligfield et al. (1983) clearly demonstrated that LFAMS tracks progressive deformation in sedimentary rocks. Many of these early studies assumed that ferromagnetic (s.l.) minerals were responsible for the observed magnetic fabrics, because of their high susceptibility and potentially high degree of anisotropy. As the number of AMS studies increased, it became obvious that paramagnetic and even diamagnetic phases can also contribute to the magnetic anisotropy (e.g., Borradaile et al. 1986, 1987; Borradaile 1987, 1988; Henry 1989, 1992; Hrouda 1986, 1987; Ihmlé et al. 1989; Rochette 1987; Rochette and Fillion 1988). Rochette (1987) suggested that on a first order, one can 
distinguish between a magnetic fabric dominated by diamagnetic, paramagnetic, or ferromagnetic (s.l.) phases based on the bulk susceptibility and degree of anisotropy. In the case that the bulk susceptibility is $<300 \times 10^{-6} \mathrm{SI}$ and the degree of anisotropy is $<35 \%$, then ferromagnetic minerals are most likely not responsible for the AMS. If the susceptibility is close to zero, then diamagnetic phases may contribute to the total magnetic fabric.

It is now recognized that the anisotropy carried by a rock or sediment can have diamagnetic, paramagnetic, ferromagnetic (s.s.), ferrimagnetic, and/or antiferrimagnetic subfabrics. There have been several excellent reviews, which describe different methods that are currently being used to measure AMS in both low and high fields (e.g., Borradaile and Henry 1997; Borradaile and Jackson 2004; Hrouda et al. 2009b; Martín-Hernandez and Férre 2007; Tarling and Hrouda 1993) and the anisotropy of remanent magnetization (Hirt 2007; Jackson 1991; Lowrie 1989; Potter 2004). These studies describe how magnetic subfabrics can be isolated using experimental methods or models. High-field measurements of AMS (HFAMS) allow the separation of the saturated ferrimagnetic torque from the diamagnetic and paramagnetic torque signal that is related linearly to the square of the applied field (Owens and Bamford 1976; Hrouda and Jelínek 1990; Tarling and Hrouda 1993; Martín-Hernández and Hirt 2001; Martín-Hernandez and Férre 2007). The torque due to hematite is related linearly to the applied field, and this property was used by Martín-Hernández and Hirt (2004) to isolate the hematite subfabric in deformed Permian red beds from the Glarus Nappe.

Low temperature has also been used as a means to enhance the paramagnetic susceptibility and its anisotropy (e.g., Hirt et al. 1993, 1995; Ihmlé et al. 1989; Pares and van der Pluijm 2002; Richter and Van der Pluijm 1994; Rochette et al. 1983). Schmidt et al. (2007a) showed that the degree of anisotropy of paramagnetic carbonate phases increases at low temperature, because both the paramagnetic susceptibility constant and paramagnetic Curie temperature show a directional dependency. In a further study, Schmidt et al. (2007b) showed that in certain cases, the anisotropy due to diamagnetic minerals can be separated from the paramagnetic subfabric. The method is dependent on the fact that any change in susceptibility as a function of temperature is only due to the paramagnetic behavior. It also assumes that the paramagnetic Curie temperature is well below the temperature used to measure the magnetic anisotropy. The authors noted, however, that any contribution due to magnetite undergoing the Verwey transition or hematite undergoing the Morin transition would falsify results.

The ability to isolate individual magnetic subfabrics aids in our understanding of which mineral phase or phases are responsible for a measured magnetic anisotropy. This is important for relating the AMS to a geologic phenomenon, e.g., compaction, deformation, flow alignment. This study reviews how different methods can be applied in order to correctly identify the carrier of magnetic fabric for a series of different rock types. Examples are considered for rocks in which the origin of the magnetic anisotropy is diamagnetic, paramagnetic, ferrimagnetic, or some mixture of the three.

\section{Anisotropy parameters}

Magnetic anisotropy is described mathematically by a second-order tensor and can be geometrically represented by an ellipsoid with principal axes $k 1 \geq k 2 \geq k 3$. Many parameters have been proposed in the past to characterize the degree of anisotropy and shape of the anisotropy ellipsoid (cf., Tarling and Hrouda 1993). Some parameters use the magnitudes of the principal axes of the anisotropy ellipsoid (i.e., eigenvalues of the susceptibility tensor), whereas others are based on eigenvalues of the deviatoric susceptibility tensor. The latter are commonly used for measurements made on torsion magnetometers, which can only measure the deviatoric susceptibility. Several parameters that are used to describe the anisotropy in a material have become more established, which is useful when comparing results in the literature. These are listed below.

The average or bulk susceptibility can be described by its arithmetic mean,

$k_{a}=\frac{k 1+k 2+k 3}{3}$,

or its geometric mean,

$k_{g}=\sqrt[3]{k 1 \cdot k 2 \cdot k 3}$.

The arithmetic mean is commonly used to define the bulk susceptibility. However, when AMS data is being compared to a texture or strain ellipsoid, the geometric mean is often used, because it describes the radius of the initial undeformed sphere. Different parameters have also been used to define the intensity of the anisotropy. These include $P$ (Nagata 1961), $P^{\prime}$ (Jelinek 1981), $k^{\prime}$ (Jelínek 1984), and $\Delta k$ (Schmidt et al. 2006) and are defined as:

$P=\frac{k 1}{k 3}$;

$P^{\prime}=\exp \sqrt{\left\{2\left(\ln k 1-\ln k_{g}\right)^{2}+\left(\ln k 2-\ln k_{g}\right)^{2}+\left(\ln k 3-\ln k_{g}\right)^{2}\right\}} ;$

$k^{\prime}=\sqrt{\frac{(k 1-k)^{2}+(k 2-k)^{2}+(k 3-k)^{2}}{3}}$ 
where $(k 1-k) \geq(k 2-k) \geq(k 3-k)$ are the deviatoric principal susceptibilities and $\Delta k=k 1-k 3 . P^{\prime}$ and $k^{\prime}$ consider the magnitudes of all three axes in their definition. $k^{\prime}$ and $\Delta k$ are useful when only the deviatoric susceptibility tensor is defined.

Many parameters have been proposed to describe the shape of the anisotropy ellipsoid. Jelinek's $T$-parameter is most commonly used, because it limits the shape to a value between \pm 1 with +1 being a rotational oblate ellipsoid, -1 a rotational prolate ellipsoid, and 0 for a neutral ellipsoid.

$T=\left[\frac{2 \ln (k 2 / k 3)}{\ln (k 1 / k 3)}\right]-1$ (Jelinek 1981).

Jelinek (1981) proposed this parameter so that $T=0$ corresponds to the ellipsoid of plane strain in structural geology. Parameters that are not dependent on the bulk susceptibility include the $V$-parameter, which defines the angle between the two circular sections that cut an ellipsoid, and $U$-parameter.

$V=\sin ^{-1} \sqrt{\frac{k 2-k 3}{k 1-k 3}}($ Graham 1966)

$V$ varies from $0^{\circ}$ to $<45^{\circ}$ for a prolate ellipsoid and $>45^{\circ}$ to $90^{\circ}$ for an oblate ellipsoid. $V=45^{\circ}$ for a neutral ellipsoid.

$U=\frac{2 k 2-k 1-k 3}{k 1-k 3}($ Jelinek 1981).

$U$ is also based on the deviatoric susceptibility tensor and ranges between \pm 1 similar to the $T$-parameter.

Tarling and Hrouda (1993) commented on the variety of parameters used to describe anisotropy ellipsoids and problems related to some parameters. They made an appeal for the use of $P^{\prime}$ to describe the degree of anisotropy and $T$ to describe the shape. These parameters are useful when the bulk susceptibility is known; however, in the case in which the deviatoric tensor is measured, $k^{\prime}, \Delta k$, and $U$ can be used. $P$ and $P^{\prime}$ differ by $<5 \%$, when the degree of anisotropy is low, but $P$ will describe a lower degree of anisotropy when the anisotropy is strong. $P^{\prime}$ and $k^{\prime}$ are not equivalent directly, but also show a quasi-linear relationship for low degree of anisotropy. Jelinek (1981) states that the shape parameters $T$ and $U$ are similar when the degree of anisotropy is low. $T$ and $U$ will always agree for rotational oblate and prolate ellipsoids. The two parameters diverge when the degree of anisotropy increases, especially when ellipsoids are neutral in shape, i.e., $T \approx 0$. Taking an extreme case where the principal axes $k 1: k 2: k 3$ are 10:1:0.1, $T=0$, following the convention that in the case of plane strain where the ratio of the maximum over the intermediate axes is equal to the ratio of the intermediate over the minimum axis. $U=-0.82$, which reflects the extreme prolate shape of the ellipsoid. Therefore, the choice of parameter may be dictated by the method used to measure the anisotropy, but only the same parameters should be compared to one another.

\section{Magnetic subfabrics}

The following section provides examples for cases where (1) AMS is controlled by diamagnetic minerals or a mixture of diamagnetic and paramagnetic minerals and (2) paramagnetic minerals or a mixture of paramagnetic and ferrimagnetic minerals contribute to the total anisotropy. Purely diamagnetic fabrics are rare in natural settings, and interpretation of AMS data can be difficult when the strengths of the diamagnetic and paramagnetic subfabrics are similar. Isolating the individual diamagnetic and paramagnetic subfabrics can present a clearer picture of the deformation that a rock has undergone. Whether ferromagnetic (s.l.) minerals control AMS is not necessarily related to the strength of the bulk susceptibility, and examples are provided that demonstrate the advantage of isolating magnetic subfabrics for rocks with a range of bulk susceptibilities.

Diamagnetic and diamagnetic-paramagnetic subfabrics

\section{Diamagnetic minerals}

Calcite and quartz are the most common diamagnetic minerals found in rocks. Limestone can contain high enough concentration of calcite and quartzite high concentration of quartz, so that their bulk susceptibilities are negative. However, due to their low susceptibility, small concentrations of paramagnetic minerals, e.g., chlorite or mica, or ferromagnetic (s.l.) minerals, may result in positive bulk susceptibility for the rock. Reports on purely diamagnetic fabrics are rare in the literature (Almqvist et al. 2009; Borradaile et al. 1999; de Wall et al. 2000; Hirt et al. 2000; Hrouda et al. 2000; Owens and Bamford 1976; Owens and Rutter 1978).

Hrouda (2004) pointed out that commercial instruments rank principal susceptibilities according to their absolute values. Therefore, for diamagnetic susceptibilities, the most negative value will be assigned to $k 1$. This assignment complicates definition of the shape ellipsoid, e.g., calcite is represented by a prolate ellipsoid, such that $k 1$ will be oriented normal to a plane of flattening. For this reason, Hrouda (2004) and Schmidt et al. (2006) recommend ranking the principal axes by their signed values, so that calcite and quartz are represented by oblate ellipsoids.

Hrouda (1986) undertook a systematic study of the AMS of pure quartz, single crystals and showed that their bulk susceptibility is around $-14 \times 10^{-6}$ (SI) and their anisotropy is $<1 \%$, in agreement with results of Nye (1957). Furthermore, he demonstrated that HF-AMS using 
high-field torque magnetometry, which measures susceptibility differences, was more sensitive in detecting weak fabrics than LF-AMS. The addition of a very small paramagnetic or ferromagnetic (s.l.) component to the quartzite leads to near-zero bulk susceptibility, due to the addition of a weak positive susceptibility. For this case, the $P$-factor becomes very high, which gives a false impression that a material has a high degree of anisotropy (see also Rochette 1987; Rochette et al. 1999; Férre 2002).

This effect can also be shown for the single crystals of calcite (Schmidt et al. 2006; 2007a; Fig. 1a). The authors made a detailed study of the intrinsic anisotropy in calcite and carbonate minerals and noted that HF-AMS was more accurate in determining the magnetic anisotropy in minerals with low bulk susceptibility. They demonstrated that bulk susceptibility and AMS are sensitive to the substitution of other cations for $\mathrm{Ca}^{2+}$. For example, the bulk susceptibility of pure $\mathrm{CaCO}_{3}$, i.e., calcite with $<200$ ppm Fe or $\mathrm{Mn}, \quad$ is $-4.46 \pm 0.16 \times 10^{-9} \mathrm{~m}^{3} / \mathrm{kg} \quad(-12.09 \pm$ $0.5 \times 10^{-6}(\mathrm{SI})$, but increases by $2.3 \times 10^{-10} \mathrm{~m}^{3} / \mathrm{kg}$ per $100 \mathrm{ppm} \mathrm{Fe}$ and $3.4 \times 10^{-10} \mathrm{~m}^{3} / \mathrm{kg}$ per $100 \mathrm{ppm} \mathrm{Mn}$. The shape of the anisotropy ellipsoid also changes. For Fecontent above $400 \mathrm{ppm}$, the anisotropy ellipsoid changes from rotational oblate to rotational prolate. Since torque magnetometry was used in these studies, $\Delta k$ and $U$ were used to describe the degree of anisotropy and shape of the anisotropy ellipsoid, respectively. Because these parameters are not dependent on bulk susceptibility, they are not affected for the case where bulk susceptibility is near zero (Fig. 1b). Almqvist et al. (2010) demonstrated that this change is also observed in natural rocks. For this reason, $\Delta k$ provides a more accurate representation of the degree of anisotropy in rocks and minerals with near-zero susceptibility.

\section{Diamagnetic-paramagnetic subfabrics}

The magnetic fabric of most rocks and sediments is not purely diamagnetic in origin; therefore, the diamagnetic subfabric should be isolated in order to compare it to a mineral fabric. Early attempts to isolate the diamagnetic subfabric by subtracting the tensor due to the ferrimagnetic subfabric, determined from the anisotropy of a remanent magnetization, from the LF-AMS tensor has been shown to be problematic (Hrouda et al. 2000). A more reliable method is by exploiting the temperature independence of diamagnetic susceptibility in high-field measurements. Schmidt et al. (2007b) demonstrated that after removing any ferrimagnetic and antiferromagnetic contribution to the total anisotropy, the diamagnetic subfabric could be isolated from the paramagnetic subfabric. This requires knowledge of the increase in the degree of anisotropy of the paramagnetic fabric at low temperature. Since most low temperature measurements are made in liquid nitrogen, Schmidt et al. (2007b) called this factor as $p_{77}$,

$p_{77}=\frac{\Delta^{\mathrm{LT}} k^{\text {para }}}{\Delta^{\mathrm{RT}} k^{\text {para }}}$

where LT indicates $\Delta k$ of the paramagnetic subfabric measured at low temperature, in this case $77 \mathrm{~K}$, and RT indicates $\Delta k$ of the paramagnetic subfabric measured at room temperature. The ratio is dependent on the specific paramagnetic phase and its composition and assumes that the anisotropy of the paramagnetic minerals is either rotationally oblate or rotationally prolate. Schmidt et al. (2007a) determined the value for common carbonate minerals and found that the $p_{77}$ factor for calcite containing $500 \mathrm{ppm}$ to $10,000 \mathrm{ppm} \mathrm{Fe}^{2+}$ is 13.3 and for siderite $\left(>370,000 \mathrm{ppm} \mathrm{Fe}^{2+}\right)$ is 7.2. Biedermann (2008) determined the factor for a collection of micas and chlorite. Biotite has the largest increase in its anisotropy at $77 \mathrm{~K}$, with $p_{77}=12.2$, and muscovite, phlogopite, and chlorite have $p_{77}$ values around 7.9 on average. To properly isolate diamagnetic and paramagnetic subfabrics, however, more information on $p_{77}$ factors for all the common paramagnetic rock-forming minerals is needed. This includes understanding how the factor varies with variations in composition for a specific mineral.
Fig. 1 Example of parameters used to describe the degree of anisotropy for the case of nearzero susceptibility in single crystals of calcite that were used in the study of Schmidt et al. (2006)
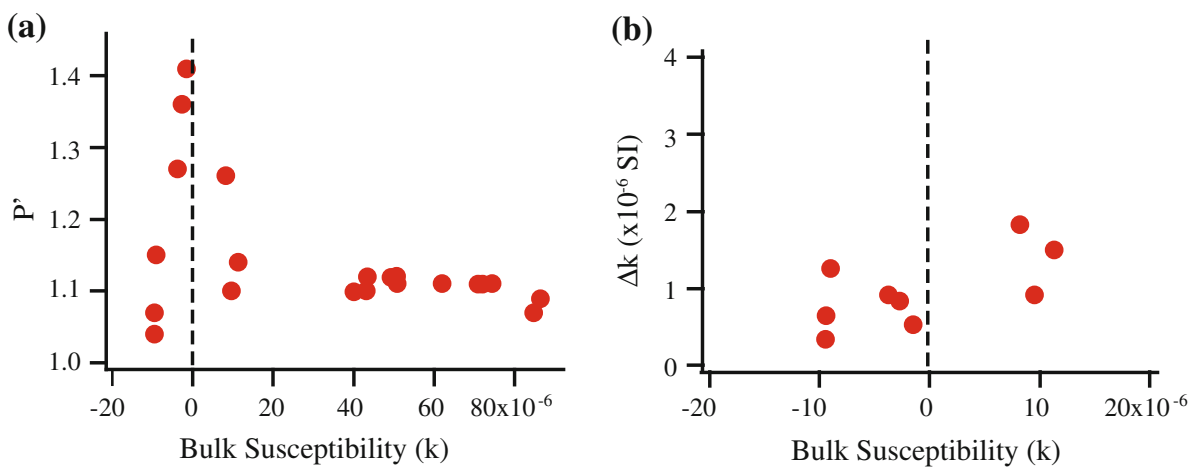
Figure 2 exemplifies how the choice in the value of $p_{77}$ will influence both the shape of the isolated diamagnetic and paramagnetic subfabrics and the direction of the principal axes in two samples from the Carrara marble. The first example is for a marble that is made up of diamagnetic calcite with a small paramagnetic contribution from iron-rich calcite. The sample has a bulk susceptibility $-8.61 \times 10^{-6}(\mathrm{SI})$. A change in the $p_{77}$ factor has the largest effect on the value of $\Delta k$ of both the diamagnetic and paramagnetic subfabrics. The shape of the ellipsoid $(U)$ and the directions of the principal axes show little change, but it is clear that the calcite fabric is oblate and the iron-rich calcite is prolate as expected (cf. Schmidt et al. 2006). The second example is for a marble with a high mica concentration (15 to $25 \%$ ) and a bulk susceptibility of $114 \times 10^{-6}(\mathrm{SI})$, which is high enough to suggest that a diamagnetic fabric would not be important. The paramagnetic subfabric shows only a small difference in the orientation of the principal axes and shape of the paramagnetic ellipsoid, with the largest change being in $\Delta k$. The diamagnetic fabric, however, shows major changes in $U, \Delta k$, and the orientation of principal axes. Choice of a $p_{77}$ value between 7 and 8 leads to an inversion of the $k 1$ and $k 3$ axes accompanied by a change from an oblate to prolate ellipsoid. It is worth noting that the only $p_{77}$ value that produces a plausible diamagnetic $\Delta k$ is $p_{77}=8$, where $\Delta k=9.49 \times 10^{-7}$ SI. For other values of $p_{77}$, the $\Delta k$ is larger than $1.10 \times 10^{-6} \mathrm{SI}$, which represents the diamagnetic $\Delta k$ for a single crystal of calcite. This case illustrates the need in choosing the correct value for separating a diamagnetic subfabric, since both the degree of anisotropy and shape of the ellipsoid will be affected.

Based on a collection of synthetic calcite-muscovite aggregates that were compressed with a known uniaxial load, Schmidt et al. (2009) showed that the diamagnetic subfabric could be isolated if it made up $>5 \%$ of the total anisotropy. A measure on how well the subfabric can be separated is demonstrated by how well the diamagnetic subfabric is quantitatively linked to calcite texture, which was determined from neutron diffraction goniometry (Fig. 3a). Aggregates consist of both $100 \%$ calcite and $100 \%$ muscovite, or mixtures of calcite with 5, 10, 30, 50, and $70 \%$ muscovite. Calcite contributed to more than $5 \%$ of the total anisotropy for the samples containing $\leq 30 \%$ muscovite. There is a very good agreement between the measured $\Delta k$ and the predicted degree of anisotropy, and differences between modeled and measured values are within the range of accuracy of the measurements. These results demonstrate the validity of separating diamagnetic subfabrics.

The following example illustrates the advantage of being able to separate diamagnetic and paramagnetic subfabric in natural rocks from the Morcles Nappe in southwestern Switzerland (Almqvist et al. 2011). The weakly deformed limestone from La Grand Vire, which is located near to the frontal folds of the nappe structure, has very low bulk susceptibility. The LF-AMS was measured with an Agico KLY-2 Kappabridge and from the 25 cores sampled at the site; only 6 cores had an anisotropy that was statistically significant, based on the f-factor and confidence values for $\mathrm{e}_{\mathrm{ij}}$ values (Jelinek 1977) (Fig. 4a). This would suggest that the limestone is undeformed. Most of the specimens have diamagnetic bulk susceptibility between $-11.3 \times 10^{-6} \mathrm{SI}$ and $-1.3 \times 10^{-6} \mathrm{SI}$, and HFAMS at room temperature and $77 \mathrm{~K}$ shows no significant ferromagnetic (s.l.) contribution to the AMS. The isolated diamagnetic and paramagnetic subfabrics are well defined and controlled by cleavage flattening (Fig. $4 \mathrm{~b}, \mathrm{c}$ ). The paramagnetic subfabric also shows a clear lineation coinciding with the stretching lineation. In addition, there is a strong correlation between the separated diamagnetic subfabric and predicted AMS from the calcite texture in these deformed limestone rocks, which further confirms the ability of the method to isolate mineral subfabrics (Almqvist 2010).

Paramagnetic and paramagnetic/ferrimagnetic subfabrics

\section{Paramagnetic subfabrics}

In the case of a rock that is solely controlled by the paramagnetic minerals, the paramagnetic subfabric is related to the intrinsic susceptibility of the constituent minerals and their degree of alignment. It should be possible to model the shape and degree of the AMS from mineral texture for a rock whose anisotropy is carried by paramagnetic phases, similar to what Schmidt et al. (2009) demonstrated for the diamagnetic fabric in the synthetic calcite-muscovite aggregates. The muscovite texture was determined with neutron diffraction on the same samples used for the AMS measurements. Figure $3 \mathrm{~b}$ shows $\Delta k$ as a function of the texture strength. There is a good agreement between the measured and predicted values of $\Delta k$. Deviation from the predicted value is higher for samples made up of 70 and $50 \%$ muscovite. Because the paramagnetic subfabric was strong and well defined in these samples, Schmidt et al. (2009) postulated that the error arose from the texture due to overlapping diffraction peaks of calcite and muscovite, which would lead to erroneous determination of texture intensity. Errors may also arise in comparing texture and AMS if both measurements are not made on the same volume of material. Martín-Hernández et al. (2005) provide an example for a case in which texture was determined by X-ray goniometry over an area of around $40 \mathrm{~mm}^{2}$ and a penetration depth of $\leq 100 \mu \mathrm{m}$ compared to AMS, which is 

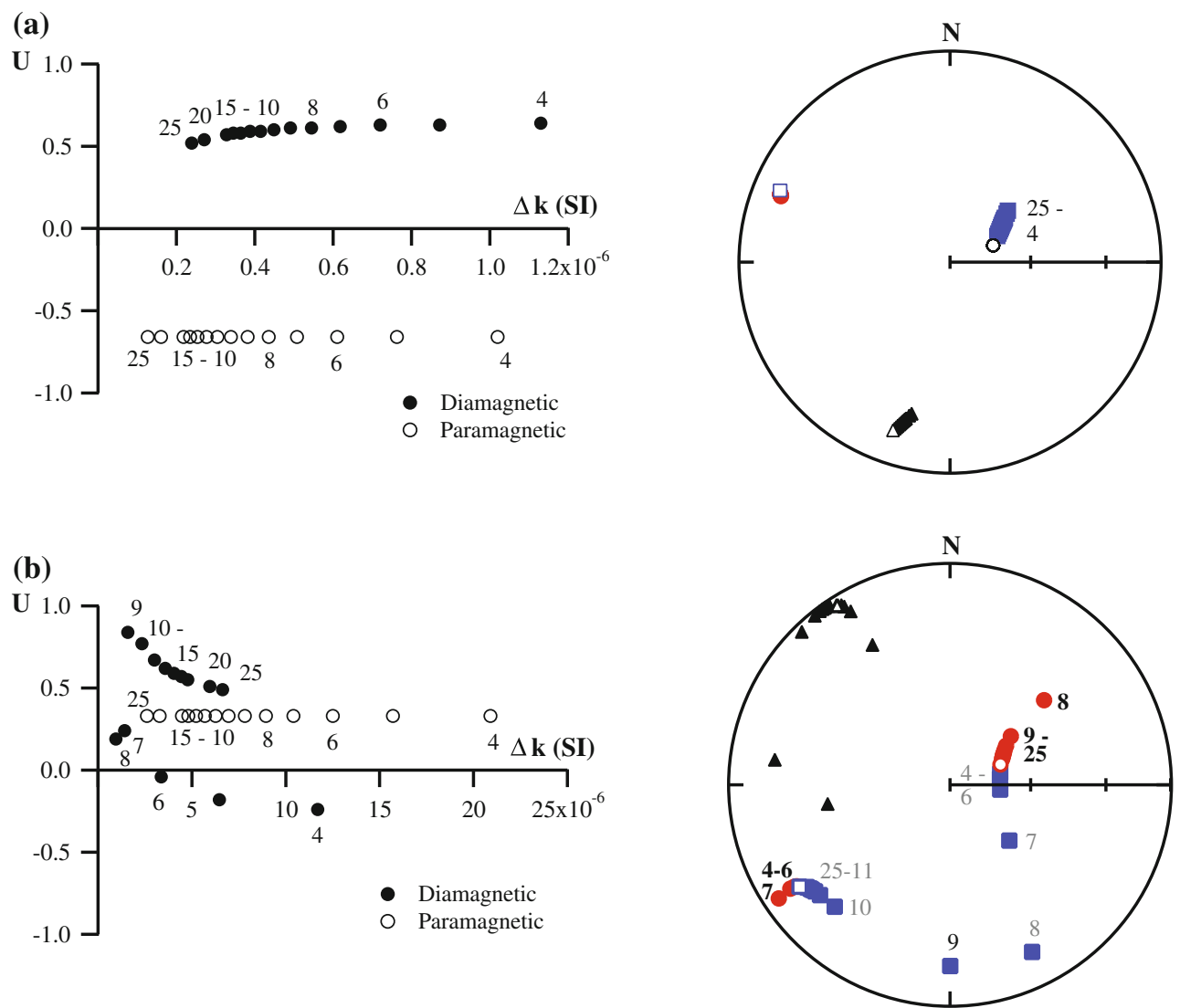

Fig. 2 Plot of $\Delta k$ versus $\mathrm{U}$ as a function of the factor $p_{77}$ for the separated diamagnetic and paramagnetic subfabrics for a Carrara marble containing calcite with variable $\mathrm{Fe}^{2+}$ content and iron-rich calcite, and $\mathbf{b}$ a limestone containing muscovite. Equal-area nets are plotted on the lower hemisphere with $k 1$ plotted as squares, $k 2$ plotted as triangles and $k 3$ plotted as circles in this and subsequent figures. Directions are shown as a function of different $p_{77}$ factors. Note that in $\mathbf{b}, \mathrm{p} 77$ values for the $k 3$ axes are in bold and for $k 1$ in gray

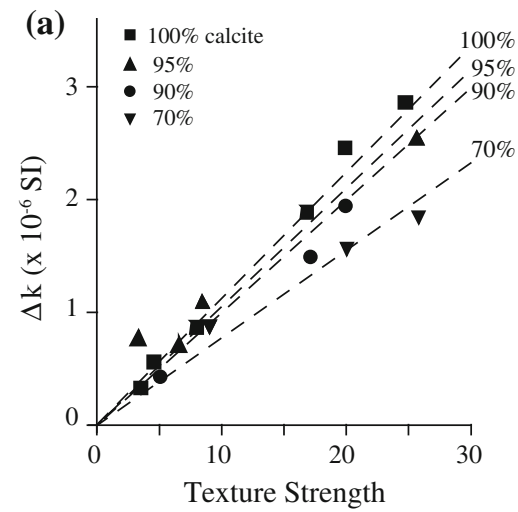

Fig. 3 Comparison between degree of anisotropy and mineral texture strength for synthetic calcite-muscovite aggregates (modified from Schmidt et al. 2009); a $\Delta k$ due to the diamagnetic subfabric as a function of texture strength of calcite for different calcite content. b $\Delta k$ due to the paramagnetic subfabric as a function of texture strength of muscovite for different muscovite content. Dashed lines

based on a cylindrical core with a volume of $11.4 \mathrm{~cm}^{3}$. For this reason, a comparison is only valid if the deformation is homogeneous on the same order of size. Debacker et al.

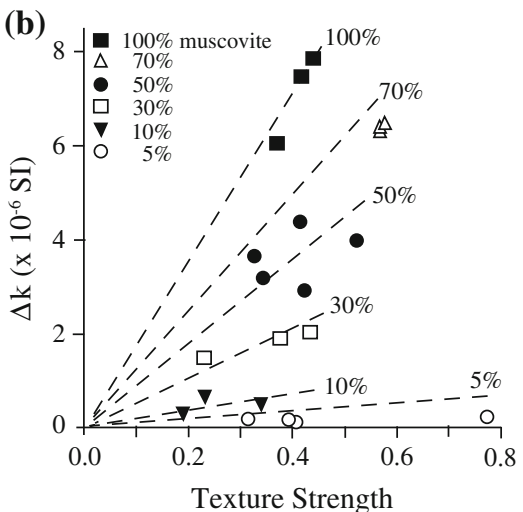

show the predicted increase in $\Delta k$ for an increase texture strength based on the intrinsic anisotropy of the respective minerals. Error bars indicate the error associated with each measurement point, in which error in $\Delta k$ is based on the precision of high-field torque magnetometer and the error in the texture is based on a comparative study by Wenk (1991)

(2004) also noted a discrepancy between texture and magnetic fabric in mudstones from the Brabant massif. They defined the texture using recrystallized fine-grained 
(a)

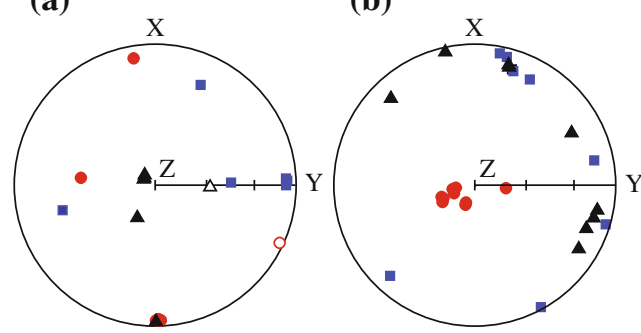

Fig. 4 Lower hemisphere equal-area stereonets showing the orientation of the principal axes of the anisotropy ellipsoid from limestone sample taken at La Grand Vire in the Morcles Nappe, Switzerland, for a LF-AMS, b diamagnetic subfabric, c paramagnetic subfabric, and (c)

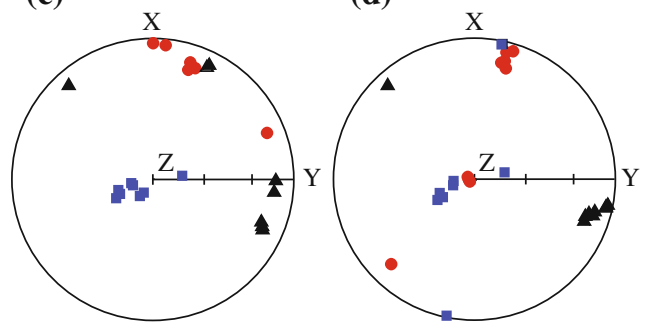

d HF-AMS at $77 \mathrm{~K}$. Samples are oriented with respect to their structural features where $X$ indicates the macroscopic lineation and $Z$ the axis to the cleavage plane

phyllosilicate minerals, but the magnetic fabric agreed with the orientation of the detrital, coarse-grained phyllosilicate phases seen in thin section. This last example is discussed further below.

In the case where the exact carrier of the paramagnetic subfabric is not known, modeling can aid in the interpretation. Figure 5 shows an example from black shale from the Martinsburg Formation, Central Appalachian foldthrust belt (Hirt et al. 2004). HF-AMS indicates that the magnetic fabrics arise only from paramagnetic phases. Biotite and chlorite are the most common paramagnetic minerals in the shale, and their textures were measured using X-ray texture goniometry. The directions of the principal axes of the paramagnetic subfabric agree with those of the texture ellipsoid for both the chlorite and mica textures, which are coaxial (Fig. 5a, b). The shape of the anisotropy ellipsoid and the degree of anisotropy are modeled using the mineral textures and intrinsic anisotropy of chlorite and biotite as end members (Martín-Hernández and Hirt 2003). The anisotropy of the black shale is more compatible with biotite as the principal carrier of the AMS (Fig. 5c). Similar attempts to model the carrier of paramagnetic subfabric by Martín-Hernández et al. (2005) in the Luarca slates from Northern Spain were not always successful. They suggested that differences could arise if (1) the fabric is heterogeneous; (2) there is a false assumption about the mineral fraction responsible for the magnetic fabric; or (3) the intrinsic anisotropy of the single phases is incorrect.

\section{Paramagnetic-ferrimagnetic subfabrics}

The following example is for samples of deformed gneiss from the Hays Mill Formation in the Piedmont Province of the Southern Appalachian Mountains and considers Rochette's (1987) observation for empirical data. HF-AMS allows for the isolation of a ferrimagnetic and paramagnetic subfabric in the samples (Fig. 6). The gneisses all have similar values of bulk susceptibility as seen from samples HM14, 16 and 38, except for samples within shear zones (HM22), whose bulk susceptibilities are an order of magnitude higher (Table 1). The bulk susceptibility is significantly $>300 \times 10^{-6} \mathrm{SI}$, but the degree of anisotropy as shown by $P^{\prime}$ varies between 1.20 and 2.88. From the HFAMS, it can be seen that paramagnetic minerals are responsible for a large part of the magnetic fabric in HM 14 and ferrimagnetic minerals control the anisotropy in HM16, although both samples have a combined fabric. Sample HM 38 and HM 66 are dominated by the ferrimagnetic phases as expected from the high values for $P^{\prime}$. Figure 6 illustrates further that the principal axes of LFAMS do not mirror either subfabric exactly. The isolated ferrimagnetic subfabric, however, better reflects deformation in the gneiss. Although bulk susceptibility of samples HM 14, 16 and 38 are on the same order, the ferrimagnetic contribution to the total AMS is between 36 and $94 \%$. Therefore, $P^{\prime}$ should be considered together with bulk susceptibility to speculate on the mineral carrier of the AMS. Note that it is only a first-order approximation since both subfabrics contribute to the total magnetic anisotropy.

Cooling a rock to a lower temperature will enhance the paramagnetic susceptibility, and Ihmle et al. (1989) was the first to exploit this in LF-AMS studies of carbonate rocks and Hirt and Gehring (1991) in ironstones. But as stated above, the paramagnetic anisotropy can be also enhanced as seen from the $p_{77}$ factor. The following example is from the Rose Hill Formation, at the site in which Graham (1949) carried out the first-fold test in paleomagnetism. The principal axes of the LF-AMS are scattered after correction for bedding tilt, although the anisotropy of individual samples is between 4 and $8 \%$, which is typical for a deformed sedimentary rock (Fig. 7a), Graham (1949) pointed out that the rocks contain a significant amount of siderite. Schmidt et al. (2007a) showed that the degree of anisotropy for siderite increases by a factor of 7.2 upon cooling to $77 \mathrm{~K}$, when compared to the degree of anisotropy at room temperature. Cooling to $77 \mathrm{~K}$ leads to a magnetic fabric in which $k 1$ axes are nearly subnormal to 
(a)

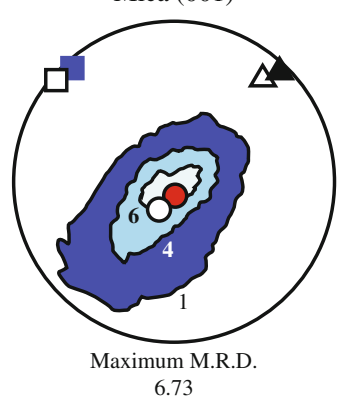

(b)

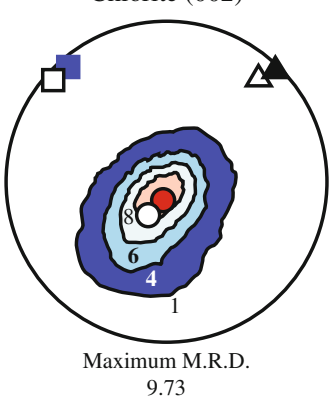

(c)

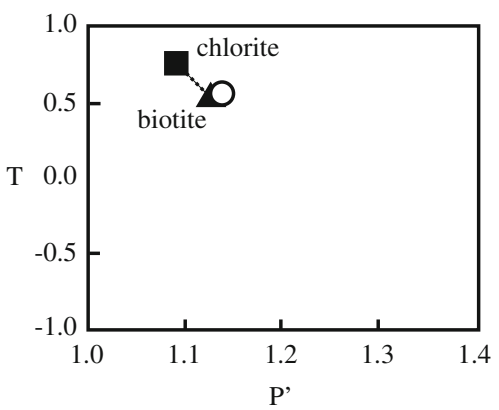

Fig. 5 a Crystallographic-preferred orientation of phyllosilicate basal poles for biotite and $\mathbf{b}$ chlorite expressed in a contour plot as multiples of random distribution (m.r.d.) for a black shale from the Martinsburg Formation. Open symbols represent the AMS ellipsoid. Closed symbols represent the texture ellipsoid, where the maximum axes are plotted with circles, intermediate axes with triangles, and minimum axes with squares. c Jelinek plot showing the predicted values for $T$ and $P^{\prime}$ for a fabric composed of $100 \%$ chlorite by the square symbol and $100 \%$ biotite by the triangle. A combination of chlorite and muscovite would follow the dotted line
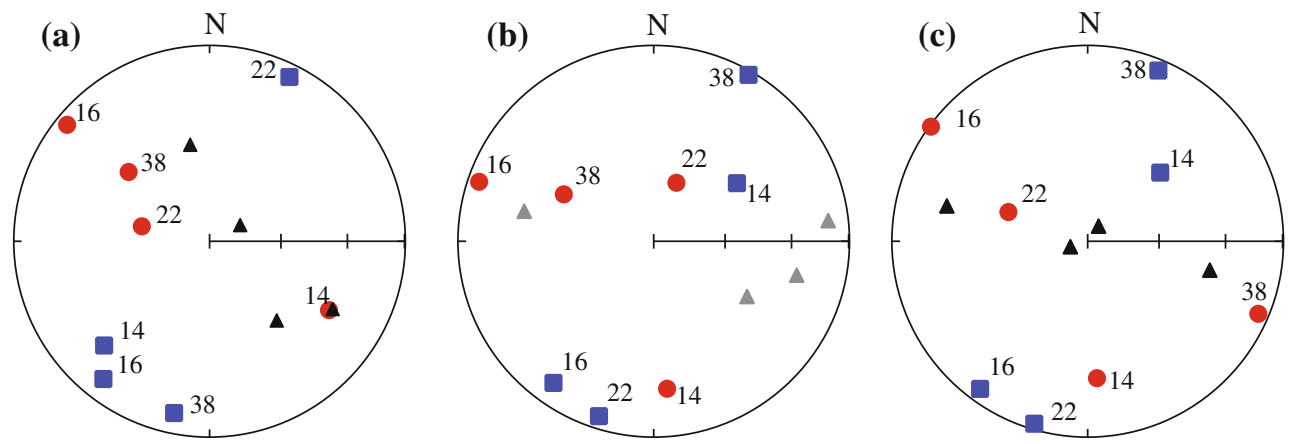

Fig. 6 Lower hemisphere, equal-area nets showing the principal axes of: a LF-AMS, b paramagnetic subfabric, and $\mathbf{c}$ ferrimagnetic subfabric from granitic gneisses of the Hays Mills Formation, Southern Appalachian fold belt

Table 1 Bulk susceptibility and degree of anisotropy for granitic gneisses from the Hays Mill Formation

\begin{tabular}{lccll}
\hline Sample & $k\left(10^{-3} \mathrm{SI}\right)$ & $P^{\prime}$ & $\begin{array}{l}\text { \% Ferrimagnetic } \\
\text { subfabric }\end{array}$ & $\begin{array}{l}\% \text { Paramagnetic } \\
\text { subfabric }\end{array}$ \\
\hline HM14 & 1.64 & 1.20 & $36 \pm 3$ & $64 \pm 3$ \\
HM16 & 1.82 & 1.32 & $70 \pm 3$ & $30 \pm 2$ \\
HM38 & 2.99 & 2.87 & $94 \pm 3$ & $6 \pm 2$ \\
HM22 & 14.8 & 3.47 & $95 \pm 7$ & $5 \pm 2$ \\
\hline
\end{tabular}

the bedding plane for most samples (Fig. 7b). Such an inverse magnetic fabric is compatible with siderite as the carrier of the anisotropy. The ferromagnetic (s.l.) fabric was determined using the anisotropy of anhysteretic remanent magnetization (AARM) acquired with a $150 \mathrm{mT}$ alternating field and a superimposed $0.1 \mathrm{mT}$ DC bias field. Magnetite is the main ferromagnetic (s.l.) phase in the rocks (French and Van der Voo 1979) and shows flattening in the bedding, as well as a statistically significant grouping of the $k 1$ axes close to the direction of the fold axis (Fig. 7c). The ferromagnetic (s.l.) minerals show the best grouping of the $k 3$ axes around the pole to bedding, and the $k 1$ axes are loosely grouped in the direction of the horizontal fold axis at the outcrop.

An important consideration when measuring AMS at low temperature is the fact that different paramagnetic minerals have different $p_{77}$ factors. Therefore, measurement of either LF-AMS or HF-AMS at $77 \mathrm{~K}$ can lead to the preferential enhancement of a paramagnetic phase with a higher $p_{77}$ factor. An example where this is important is in a study by Debacker et al. (2009), who noted a discrepancy between the different magnetic subfabrics determined by different methods and the orientation of the texture ellipsoid determined for mica and chlorite using X-ray texture goniometry. Figure 8 shows an example for a site in the Silurian Vichenet Formation from the Anglo-Brabant Deformation Belt in Belgium. This mudstone is composed largely of white mica, chlorite, and quartz. LF-AMS was measured at room temperature and $77 \mathrm{~K}$, HF-AMS was used to isolate the paramagnetic subfabric, and AARM was used to define the anisotropy of the ferromagnetic (s.l.) phases, which was not a significant component in the HFAMS. The mica (001) and chlorite (002) pole figures show orthorhombic to girdled distributions of poles to the basal 

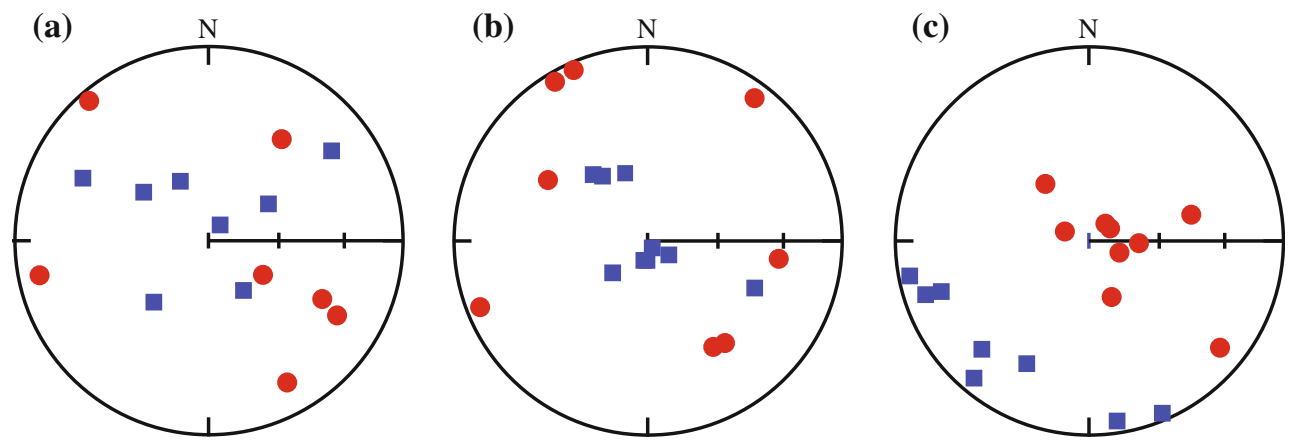

Fig. 7 Lower hemisphere equal-area projections showing principal axes for samples from the Rose Hill Formation for a LF-AMS at room temperature, b LF-AMS at 77, and $\mathbf{c}$ anisotropy of anhysteretic magnetic remanence

planes with the maximum distribution centered about the pole to cleavage. The LF-AMS at room temperature illustrates that the maximum axes are well grouped about the intersection lineation of the bedding and cleavage planes (Fig. 8a). This is also the case for the magnetic fabrics determined by the other methods (Fig. $8 \mathrm{~b}$ ). The $k 3$ axes of the room temperature LF-AMS are distributed in a plane between the pole to bedding and cleavage, whereas the low temperature LF-AMS has its $k 3$ axes close to the bedding pole (Fig. 8a). The $k 3$ of the paramagnetic subfabric isolated by HF-AMS agrees with the LF-AMS at room temperature, and the $k 3$ axes of the AARM ellipsoids are grouped around the cleavage pole (Fig. 8b). Light microscopy shows that besides the small, Fe-poor chlorite grains lying in the cleavage plane, there is a small percentage of large, Fe-rich chlorite-mica stacks that lie in the bedding plane. Chlorite and muscovite have a $p_{77}$ factor around 7.9 on average, and biotite has 12.2 on average. If the coarsegrained chlorite-mica stacks are dominated by a biotite composition, this fabric could be preferentially enhanced at low temperature and thus control the measured LF-AMS at 77 K. Debacker et al. (2009) point out that in areas that have a complicated geological history, several generations of paramagnetic phases may compete with one another, therefore influencing the total AMS. This is an interesting example on how one paramagnetic fabric can be enhanced relative to another and used for a geological interpretation.

\section{Ferromagnetic (s.l.) subfabrics}

The examples from the Rosehill and Hays Mills Formations both indicate that the ferromagnetic (s.l.) minerals best reflect rock deformation. This may not always be the case in deformed rocks and will be dependent on the ferromagnetic (s.l.) minerals in the rock, their time of genesis, i.e., primary or secondary, and the rheological contrast between the ferromagnetic (s.l.) grains and matrix minerals. Stamatakos and Kodama (1991) demonstrated that the remanent magnetization of hematite was deflected due to
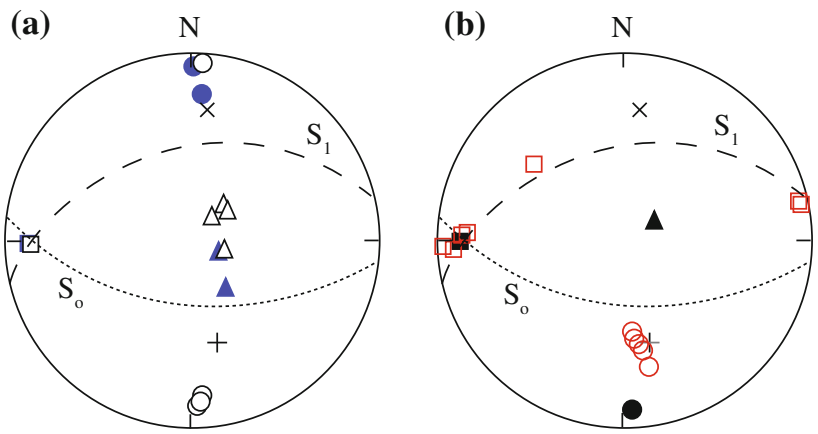

Fig. 8 Lower Hemisphere, equal-area net showing the principal axes for a mudstone from the Silurian Vichenet Formation from the AngloBrabant Deformation Belt. a LF-AMS at room temperature is shown by open symbols, and LF-AMS measured at $77 \mathrm{~K}$ is shown by filled symbols. b Paramagnetic subfabric isolated using HF-AMS for one sample is shown by filled symbol, and AARM is shown by open gray symbols. Pole to cleavage plane $\left(\mathrm{S}_{1}\right)$ is indicated by + and pole to bedding plane $\left(\mathrm{S}_{\mathrm{o}}\right)$ by $x$

flexural flow folding. They suggested that this was because hematite acted as a rigid marker in a viscous matrix during deformation and was more affected by strain. Hirt (2007) showed in another example from the Martinsburg Formation and underlying limestone of the Coburn Formation from the central Appalachian Mountains that the LF-AMS of the limestone shows a composite fabric due to an overlapping of the bedding and tectonic flattening. The magnetic fabric of the black shale only reflects bedding compaction. The AARM and ferrimagnetic subfabric isolated from HF-AMS, however, shows a composite fabric in both the limestone and shale. HF-AMS of the limestone arose solely from the ferrimagnetic minerals, whereas there was a strong paramagnetic fabric in the shales reflecting the strong, initial bedding compaction.

\section{Discussion and conclusions}

Magnetic fabric arises from petrofabrics. The contribution of individual minerals to the total magnetic anisotropy is 
dependent on the intrinsic anisotropy of the constituent minerals, their concentration, and the degree of alignment of the different phases. Petrofabric is defined by the texture, i.e., crystallographic-preferred or lattice-preferred orientation (CPO/LPO) of crystals and/or the shape-preferred orientation (SPO) of grains. The former control the anisotropy of diamagnetic, paramagnetic, and antiferromagnetic minerals, whereas the latter can dictate the anisotropy of ferrimagnetic minerals with high spontaneous magnetization. Therefore, the SPO of magnetite will generally be more important in determining its contribution to the total magnetic anisotropy for grains that deviate from a sphere, than its CPO.

The examples above illustrate how isolation of magnetic subfabrics improves our understanding of how mineral texture contributes to magnetic anisotropy. The subfabrics can then be used to better understand a range of geological features, such as deformation mechanisms, strain and the magnitude of the deformation, or flow structures in a rock. Simple assumptions about AMS carriers based on bulk properties can provide a first-order estimate of the magnetic phases that carry or contribute to the total AMS. However, when the data are compared with texture information, there are advantages in isolating the individual magnetic subfabrics. This can be particularly important when examining rocks, which have a significant diamagnetic subfabric that competes with any paramagnetic and ferromagnetic (s.l.) subfabric. Calcite has a strong intrinsic AMS and thus potentially makes a measureable contribution to the magnetic fabric in carbonaceous rocks. The example from La Grand Vire illustrates clearly that when the diamagnetic and paramagnetic subfabrics are of similar strength, the degree of anisotropy may appear insignificant. This could lead to an interpretation that the rock is not deformed, i.e., shows no mineral texture. It is also important to note that in these cases, $P$ and $P^{\prime}$ do not reflect the degree of anisotropy (Hrouda 1986; Rochette 1987), but $\Delta k$ will reflect the degree of deformation when examining rocks with bulk susceptibility around zero.

Bulk susceptibility alone is often not a good indicator for assigning a magnetic carrier of the AMS, as seen in the example from the Hays Mill Formation. Rocks with bulk susceptibility $>300 \times 10^{-6}$ SI can have a significant part of their AMS carried by paramagnetic phases or exclusively by ferromagnetic (s.l.) phases. However, as Rochette (1987) noted, if bulk susceptibility is considered together with $P^{\prime}$, it is possible to establish whether a magnetic fabric is controlled by the ferromagnetic (s.l.) phases, at least on a first order. The contribution of a diamagnetic subfabric is often ignored, and it should be noted that even carbonaceous rocks with bulk susceptibility around $1 \times 10^{-4}$ (SI) could still have a significant diamagnetic contribution to the total AMS.
Simply measuring AMS at a temperature below room temperature can enhance the paramagnetic subfabric (Fig. 4d), which will be indicated by an overall increase in susceptibility. One exception is if a paramagnetic phase undergoes magnetic blocking, which may also lead to an increase. Since the paramagnetic Curie temperature for common rock-forming minerals is often under $50 \mathrm{~K}$, restricting measurements to higher temperatures should eliminate this explanation for most cases. Studies on the low temperature anisotropy of carbonate and some common phyllosilicate minerals (Biedermann 2008; Schmidt et al. 2007a), however, show that the degree of anisotropy may also increase with a decrease in temperature. Therefore, some paramagnetic phases may be enhanced to a larger degree than others, as observed by Debacker et al. (2009). Further work is needed to establish the change in magnetic anisotropy at low temperature and define the $p_{77}$ factor for other common rock-forming minerals.

When applying magnetic anisotropy results to studies on rock deformation, separation of magnetic subfabrics can be useful in understanding deformation. Minerals can respond differently to an applied stress, e.g., they can rotate, undergo internal deformation or recrystallisation. Several examples are presented above that indicate that the ferromagnetic (s.l.) subfabric better reflects deformation in a rock. There can be several explanations why this is the case. In sediments with a high concentration of phyllosilicate minerals in the matrix, the iron-oxide phase may behave as a rigid marker in a viscous matrix. Alternatively, a ferromagnetic (s.l.) phase that crystallizes during the deformation may be influenced by the stress field at the time of formation.

With the availability of susceptibility bridges that can measure with variable AC field intensity (AGICO KLY-4 and MFK1), or frequency (AGICO MFK1), it is possible to exploit these features to further discriminate between different ferromagnetic (s.l.) fabrics. Hrouda (2009) has shown that the magnetic fabric due to multi-domain (MD) ferromagnetic minerals (s.l.) other than pure magnetite can be isolated by modeling the behavior of bulk susceptibility as a function of the applied field used in measurement of LF-AMS. Only the MD grains of titano-magnetite, pyrrhotite, and hematite exhibit field dependency (cf., Hrouda 2009). An example of how the isolated fabrics can be applied to a geologic study is shown in Hrouda et al. (2009a). The authors separate the ferromagnetic (s.l.) fabric due to pyrrhotite from that due to magnetite.

Magnetic fabrics are sensitive indicators of mineral texture and the shape-preferred orientation of ferrimagnetic minerals. The ability to isolate magnetic subfabrics is very useful when interpreting magnetic fabrics for geological applications. Many methods exist for isolating or enhancing a specific magnetic subfabric, either using experimental 
or using modeling methods. Important when employing any method is a good understanding of the assumptions behind the method. Therefore, in applying magnetic fabrics to a specific problem, it is worthwhile to first consider which magnetic subfabric will provide the most information and secondly which method should be used to measure or isolate the subfabric. This approach allows for a powerful and accurate tool to analyze mineral fabrics in a wide spectrum of geological materials.

Acknowledgments We thank E. Férre, F. Martín-Hernández and M. Chadima for their helpful reviews. The work was supported by the Swiss National Science Foundation, project 2-77070-07.

\section{References}

Almqvist BSG (2010) Physical anisotropies in deformed carbonate rocks. PhD Thesis, ETH, Zurich

Almqvist BSG, Hirt AM, Schmidt V, Dietrich D (2009) Magnetic fabrics of the Morcles Nappe complex. Tectonophysics 466(1-2):89-100. doi:10.1016/j.tecto.2008.07.014

Almqvist BSG, Herwegh M, Schmidt V, Pettke T, Hirt AM (2010) Magnetic susceptibility as a tool to study deformed calcite with variable impurity content. Geochem Geophys Geosys 11: Q01Z09. doi:10.1029/2009gc002900

Almqvist BSG, Hirt AM, Herwegh M, Leiss B (2011) Magnetic anisotropy reveals Neogene tectonic overprint in highly strained carbonate mylonites from the Morcle Nappe, Switzerland. J Struct Geol 33:1010. doi:10.1016/j.jsg.2011.02.002

Balsley JR, Buddington AF (1960) Magnetic susceptibility and fabric of some Adirondack granites and orthogneisses. Am J Sci 258-A:6-20

Biedermann A (2008) Determination of the magnetic anisotropy factor, $\mathrm{p}_{77}$, for mica and chlorite. BSc Thesis, ETH, Zurich

Borradaile G (1987) Anisotropy of magnetic susceptibility: rock composition versus strain. Tectonophysics 138:327-329

Borradaile GJ (1988) Magnetic susceptibility, petrofabrics, and strain: a review. Tectonophysics $156: 1-20$

Borradaile GJ, Henry B (1997) Tectonic application of magnetic susceptibility and its anisotropy. Earth Sci Rev 42:49-93

Borradaile GJ, Jackson M (2004) Anisotropy of magnetic susceptibility (AMS): magntic petrofabrics of deformed rocks. In: Martín-Hernandez F, Lünburg C, Auboug C, Jackson M (eds) Magnetic fabric: methods and applications, vol 238. Geological Society, London, pp 299-360

Borradaile G, Mothersill J, Tarling D, Alford C (1986) Sources of magnetic susceptibility in a slate. Earth Planet Sci Lett 76:336340

Borradaile G, Keeler W, Alford C, Sarvas P (1987) Anisotropy of magnetic susceptibility of some metamorphic minerals. Phys Earth Planet Inter 48:161-166

Borradaile GJ, Fralick PW, Lagroix F (1999) Acquisition of anhysteretic remanence and tensor subtraction from ams isolates true paleocurrent grain alignments. In: Tarling $\mathrm{DH}$, Turner $\mathrm{P}$ (eds) Diagenesis in sediments, vol 151. Geological Society, London, pp 139-145

de Wall H, Bestmann M, Ullemeyer K (2000) Anisotropy of diamagnetic susceptibility in Thassos marble: a comparison between measured and modeled data. J Struct Geol 22(11-12): 1761-1771

Debacker TN, Robion P, Sintubin M (2004) The anisotropy of magnetic suscpetibility (AMS) in low-grade, cleaved pelitic rocks: Influence of cleavage/bedding angle and type and relative orientation of magnetic carriers. In: Martín-Hernandez F, Lünburg C, Auboug C, Jackson M (eds) Magnetic fabric: methods and applications, vol 238. Geological Society, London, pp 77-108

Debacker TN, Hirt AM, Sintubin M, Robion P (2009) Differences between magnetic and mineral fabrics in low-grade, cleaved siliciclastic pelites: a case study from the Anglo-Brabant deformation belt (Belgium). Tectonophysics 466(1-2):32-46. doi:10.1016/j.tecto.2008.09.039

Férre E (2002) Theoretical models of intermediate and inverse AMS fabrics. Geophys Res Lett 29 (7):1127. doi:10.1029/2001 GL014367

French AN, Van der Voo R (1979) The magnetization of the Rose Hill formation at the classical site of Graham's fold test. J Geophys Res 84:7688-7696

Fuller MD (1960) Anisotropy of susceptibility and the natural remanent magnetization of some Welsh slates. Nature 186: 790-792

Fuller MD (1963) Magnetic anisotropy and palaeomagnetism. J Geophys Res 68:293-309

Fuller MD (1964) On the magnetic fabric of certain rocks. J Geol $72: 368-376$

Graham JW (1949) The stability and significance of magnetism in sedimentary rocks. J Geophys Res 54:131-167

Graham JW (1954) Magnetic susceptibility anisotropy, an unexploited petrofabric element. Bull Geol Soc Am 65:1257-1258

Graham JW (1966) Significance of magnetic anisotropy in Appalachian sedimentary rocks. In: Steinhart JS, Smith TJ (eds) The earth beneath the continents. Geophysical monograph 10. AGU, Washington, pp 627-648

Henry B (1989) Magnetic fabric and orientation tensor of minerals in rocks. Tectonophysics 165:21-28

Henry B (1992) Modelling the relationship between magnetic fabric and strain in polymineralic rocks. Phys Earth Planet Inter $70: 214-218$

Hirt AM (2007) Magnetic remanence, anisotropy. In: Gubbins D, Herrero-Bervera E (eds) Encyclopedia or geomagnetism and paleomagnetism. Springer, Dordrecht, pp 535-539

Hirt AM, Gehring AU (1991) Thermal alteration of the magnetic mineralogy in ferruginous rocks. J Geophys Res 96(B6):99479953

Hirt AM, Lowrie W, Clendenen WS, Kligfield R (1993) Correlation of strain and the anisotropy of magnetic susceptibility in the Onaping formation: evidence for a near-circular origin of the Sudbury basin. Tectonophysics 225:231-254

Hirt AM, Evans KF, Engelder T (1995) Correlation between magnetic anisotropy and fabric for Devonian shales on the Appalachian plateau. Tectonophysics 247:121-132

Hirt AM, Julivert M, Soldevila J (2000) Magnetic fabric and deformation in the Navia-Alto Sil slate belt, Northwestern Spain. Tectonophysics 320:1-16

Hirt AM, Lowrie W, Lüneburg C, Lebit H, Engelder T (2004) Magnetic and mineral fabric development in the Ordovician Martinsburg formation in the Central Appalachian fold and thrust belt, Pennsylvania. In: Martín-Hernandez F, Lünburg C, Auboug C, Jackson M (eds) Magnetic fabric: methods and applications, vol 238. Geological Society, London, pp 109-126

Hrouda F (1979) The strain interpretation of magnetic anisotropy in rocks of the Nízky Jeseník mountains (Czechoslovakia). Sbor Geol Ved 16:27-62

Hrouda F (1986) The effect of quartz on the magnetic anisotropy of quartzite. Stud Geophys Geod 30:39-45

Hrouda F (1987) Mathematical model relationship between the paramagnetic anisotropy and strain in slates. Tectonophysics $142: 323-327$ 
Hrouda F (2004) Problems in interpreting AMS parameters in diamagnetic rocks. In: Martín-Hernandez F, Lünburg C, Auboug C, Jackson M (eds) Magnetic fabric: methods and applications, vol 238. Geological Society, London, pp 49-60

Hrouda F (2009) Determination of field-independent and field-dependent components of anisotropy of susceptibility through standard ams measurement in variable low fields I: theory. Tectonophysics 466(1-2):114-122. doi:10.1016/j.tecto.2008.05.026

Hrouda F, Janák F (1976) The changes in the shape of the magnetic susceptibility ellipsoid during progressive metamorphism and deformation. Tectonophysics 34:135-148

Hrouda F, Jelínek V (1990) Resolution of ferromagnetic and paramagnetic anisotropies, using combined low-field and highfield measurements. Geophys J Int 103:75-84

Hrouda F, Henry B, Borradaile G (2000) Limitations of tensor subtraction in isolating diamagnetic fabrics by magnetic anisotropy. Tectonophysics 322(3-4):303-310

Hrouda F, Faryad SW, Chlupacova M, Jerabek P, Kratinova Z (2009a) Determination of field-independent and field-dependent components of anisotropy of susceptibility through standard ams measurement in variable low fields II: an example from the ultramafic body and host granulitic rocks at Bory in the Moldanubian zone of western Moravia, Czech Republic. Tectonophysics 466(1-2):123-134. doi:10.1016/j.tecto.2008.10.014

Hrouda F, Faryad SW, Jerabek P, Chlupacova M, Vitous P (2009b) Primary magnetic fabric in an ultramafic body (Moldanubian zone, European Variscides) survives exhumation-related granulite-amphibolite facies metamorphism. Lithos 111(1-2):95-111. doi:10.1016/j.lithos.2008.10.004

Ihmlé PF, Hirt AM, Lowrie W, Dietrich D (1989) Inverse magnetic fabric in deformed limestones of the Morcles Nappe, Switzerland. Geophys Res Lett 16:1383-1386

Jackson M (1991) Anisotropy of magnetic remanence: a brief review of mineralogical sources, physical origins, and geological applications, and comparison with susceptibility anisotropy. Pure Appl Geophys 136:1-28

Jelinek V (1977) The statistical theory of measuring anisotropy of magnetic susceptibility of rocks and its application. Geofyzika Brno, Brno

Jelinek V (1981) Characterization of the magnetic fabric of rocks. Tectonophysics 79:T63-T67

Jelínek V (1984) On a mixed quadratic invariant of the magnetic susceptibility tensor. J Geophys 56:58-60

Kligfield R, Lowrie W, Dalziel IWD (1977) Magnetic susceptibility anisotropy as a strain indicator in the Sudbury basin, Ontario. Tectonophysics 40:287-308

Kligfield R, Owens WH, Lowrie W (1981) Magnetic susceptibility anisotropy, strain, and progressive deformation in Permian sediments from the Maritime Alps (France). Earth Planet Sci Lett 55:181-189

Kligfield R, Lowrie W, Pfiffner OA (1982) Magnetic properties of deformed oolitic limestones from the Swiss Alps: the correlation of magnetic anisotropy and strain. Eclog Geol Helv 75:127-157

Kligfield R, Lowrie W, Hirt A, Siddans AWB (1983) Effect of progressive deformation on remanent magnetization of Permian redbeds from the Maritime Alps (France). Tectonophysics 97:59-85

Kneen SJ (1976) The relationship between the magnetic and strain fabrics of some haematite-bearing Welsh slates. Earth Planet Sci Lett 31:413-416

Lowrie W (1989) Magnetic analysis of rock fabric. In: James DE (ed) The encyclopaedia of solid earth geophysics. Van Nostrand Reinhold, New York, pp 698-706

Martín-Hernandez F, Férre EC (2007) Separation of paramagnetic and ferrimagnetic anisotropies a review. J Geophys Res 112(B3):B03105
Martín-Hernández F, Hirt AM (2001) Separation of ferrimagnetic and paramagnetic anisotropies using a high-field torsion magnetometer. Tectonophysics 337:209-222

Martín-Hernández F, Hirt AM (2003) The anisotropy of magnetic susceptibility in biotite, muscovite and chlorite single crystals. Tectonophysics 367:13-28

Martín-Hernández F, Hirt AM (2004) A method for the separation of paramagnetic, ferrimagnetic and haematite magnetic subfabrics using high-field torque magnetometry. Geophys J Int 157:117-127

Martín-Hernández F, Kunze K, Julivert M, Hirt AM (2005) Mathematical simulations of anisotropy of magnetic susceptibility on composite fabrics. J Geophys Res 110(B06102). doi:10.1029/ 2004/JB003505

Nagata T (1961) Rock magnetism, 2nd edn. Maruzen, Tokyo

Nye JF (1957) Physical properties of crystals. Oxford University Press, London

Owens WH, Bamford D (1976) Magnetic, seismic and other anisotropic properties of rock fabric. Phil Trans R Soc Lond A283:55-68

Owens WH, Rutter EH (1978) The development of magnetic susceptibility anisotropy through crystallographic preferred orientation in a calcite rock. Phys Earth Planet Inter 16:215-222

Pares JM, van der Pluijm BA (2002) Phyllosilicate fabric characterization by low-temperature anisotropy of magnetic susceptibility (LT-AMS). Geophys Res Lett 29(24):art. no.-2215

Potter DK (2004) A comparison of anisotropy of magnetic remanence methods-a user's guide for applicaiton to paleomagnetism and magnetic fabric studies. In: Martín-Hernandez F, Lünburg C, Auboug C, Jackson M (eds) Magnetic fabric: methods and applications, vol 238. Geological Society, London, pp 21-36

Richter C, Van der Pluijm BA (1994) Separation of paramagnetic and ferrimagnetic susceptibilities using low temperature magnetic susceptibilities and comparison with high field methods. Phys Earth Planet Inter 82:113-123

Rochette P (1987) Magnetic susceptibility of the rock matrix related to magnetic fabric studies. J Struct Geol 9:1015-1020

Rochette P, Fillion G (1988) Identification of multicomponent anisotropies in rocks using various field and temperature values in a cryogenic magnetometer. Phys Earth Planet Inter 51:379-386

Rochette P, Fillion G, Mollard P, Vergne R (1983) Utilisation d'un magnétomètre à effet Josephson pour l'analyse de l'anisotropie magnétique des roches. C R Acad Sc Paris 296:557-559

Rochette P, Aubourg C, Perrin M (1999) Is this magnetic fabric normal? A review and case study in volcanic formations. Tectonophysics 307:219-234

Schmidt V, Günther D, Hirt AM (2006) Magnetic anisotropy of calcite at room-temperature. Tectonophysics 418:63-73

Schmidt V, Hirt AM, Hametner K, Günther D (2007a) Magnetic anisotropy of carbonate minerals at room temperature and $77 \mathrm{~K}$. Am Miner 92(10): 1673-1684

Schmidt V, Hirt AM, Rosselli P, Martín Hernández F (2007b) Separation of diamagnetic and paramagnetic anisotropy by highfield, low-temperature torque measurements. Geophys J Int 168(1):40-47. doi:10.1111/j.1365-1246X.2006.03202.x, 02007

Schmidt V, Hirt AM, Leiss B, Burlini L, Walter J (2009) Quantitative correlation of strain, texture and magnetic anisotropy of compacted calcite-muscovite aggregates. J Struc Geol 31:1062-1073. doi:10.1016/j.jsg.2008.11.012

Stamatakos J, Kodama K (1991) The effects of grain-scale deformation on the Bloomsburg formation pole. J Geophys Res 96(B11):17919-17933

Tarling DH, Hrouda F (1993) The magnetic anisotropy of rocks. Chapman and Hall, London

Wenk HR (1991) Standard project for pole-figure determination by neutron-diffraction. J Appl Cryst 24:920-927 